\title{
Post COVID-19 Pandemic International Travel: Does Risk Perception and Stress-Level Affect Future Travel Intention?
}

\author{
Ahmad Febri Falahuddin ${ }^{1}$, Clare Teroviel Tergu' ${ }^{2}$, Rachele Brollo ${ }^{3}$, \\ Ratih Oktri Nanda ${ }^{4}$ \\ ${ }^{1}$ School of Tourism Management, Zhengzhou University, Zhengzhou 450000, P.R. China \\ (Email: ahmfebri@gs.zzu.edu.cn) \\ ${ }^{2}$ School of Tourism Management, Zhengzhou University, Zhengzhou 450000, P.R. China \\ (Email: claretergu16@gmail.com) \\ ${ }^{3}$ School of Tourism Management, Zhengzhou University, Zhengzhou 450000, P.R. China \\ (Email: rachele.brollo@gmail.com) \\ ${ }^{4}$ School of Public Health, Nanjing Medical University, Nanjing 211146, P.R. China \\ (Email: oktrinanda1910@gmail.com)
}

\begin{abstract}
The COVID-19 pandemic has extremely affected several industries including international travel and tourism. Many scholars have tried to describe the cause-effects of this major phenomenon. This study majorly aims to explore the relationship between risk perception and travel intention where stress level prone to COVID-19 quarantine serves as a moderating factor. The researchers believed that the influence of the dimensions of risk perception including social risk, psychological risk, physical risk, performance risk, financial risk and time risk on travel intention will be significant when the variable of stress level intervenes. This paper used a quantitative approach involving 409 respondents around the world. The data were gathered via online questionnaires facilitated by Google form and Wenjuanxing. The respective questionnaires were available in five languages (Chinese, English, Italian, French and Indonesian). Both descriptive and inferential statistics were used to analyze the data. The outcome of the hierarchical multiple regression (HMR) test resulted in a positive connection between all independent variables and travel intention simultaneously but not partially. The uppermost influence was found in social risk. Meanwhile, financial risk and time risk indicate no significant relationship. Lastly, the researchers believe that understanding the relationships between the variables of this study would be beneficial for the DMOs to predict the future market and rearrange strategies after being affected by the pandemic.
\end{abstract}

\section{Keywords:}

COVID-19; risk perception; stress level; travel intention

\section{Introduction}

The novel coronavirus disease (COVID-19) has affected multiple industries across the globe including international travel and tourism adversely. As volatile as the tourism industry is, it is predictable to know how heavily the COVID-19 is going to have an impact on the industry with a similar scenario in the cases of SARS and haze pollution. Tourism organizations either public, government, or NGO are all going to have a fair share of the negative effects of the COVID-19 pandemic. Riley (2020) estimated that global airlines might lose around $\$ 113$ billion in sales. Airbnb and Uber are already reporting the decline in their activities. After the COVID-19 outburst in China in December 2019, the epicenter of the pandemic has moved to Europe having a devastating impact on some popular tourist destinations such as Italy, Spain, and France. The spiking numbers of the infected cases from the United States also look worrying. 
Besides, this is not to mention India or the African countries where the COVID-19 has not penetrated so deeply yet. This paper focuses on the travel intentions of international tourists after the pandemic while taking perceived risks and stress levels concerning tourist's travel intention into consideration. In the tourism context, Ahn et al. (2013) defined travel intention as the "possibility of traveling to a destination." It threw more light on one's intent to travel or commitment to travel. Jang et al. (2009) said, "An outcome of travel intention is a mental process and transformation between motivations then into behavior." In tourism literature, travel motivation has been an important area of study for years. The need to understand and identify the various needs as to the reasons why people leave their place of residence to a place of unfamiliarity to satisfy their touristic needs and factors influencing the intentions behind their travel is beneficial to tourism planning, marketing and development. This study highlights the influence of risk perception as the determinant factor of travel intention. Some factors such as pandemic play a role to change tourist's risk perception level while they plan to visit a particular travel destination or perform any tourism activities (Fuchs \& Reichel, 2011; Hasan et al., 2017). The idea of risk perception stands for the ambiguity or uncertainty of the customers when considering purchasing a new product or service. Risk has been identified as a major concern for international travelers (Reisinger \& Mavondo, 2005). George Brooker is among many scholars who proposed the method of classifying the factors or the dimensions of risk perception. It includes social risk, physical risk, psychological risk, performance risk, financial risk, \& time risk (Brooker, 1984). Each dimension is predicted to have a significant connection to the intention to travel internationally after the pandemic. To date, the involvement of stress level to forecast intention to travel is commonly found but the use of such variables to moderate the relationship between risk perception and travel intention in a context of COVID-19 pandemic appears to be a brand-new concept. The researchers believed that the pressures resulting from the quarantine or "stay at home" policy amid the COVID-19 pandemic have elicited the change in people of how they perceive risks for international travel. Thus, this paper generally seeks the answers to these two major questions: (1) to what extent is the influence of risk perception on the intention of potential tourists to travel internationally when the COVID-19 pandemic is over? and (2) what impact does the stress level for being quarantined amid the COVID-19 pandemic have towards the relationship between risk perception and the post-pandemic international travel intention of the potential tourists?

\section{Literature Review \\ Travel Intention}

Travel intention is based on attitude and predilection toward a product or brand (Yeh \& Huan, 2014; Chen et al., 2014). According to Wu (2015), tourism behaviors are also determined by coherent and affective conditions. In other words, psychological and functional variables often influence behavior towards a destination, which leads to travel intention. Motivations are possible to identify tourist intentions as widely discussed and accepted in the study of travel motivation (Mohamed \& Othman, 2012; Mody et al., 2014; Naidoo et al., 2015). The needs of individuals are the basic ground to understand their motivation to travel. The motivation for travel must be considered when promoting destinations and dividing target markets, because motivation drives people and is thus important when choosing a destination (Sancho \& Álvarez, 2010). Referring to Maslow's five-stage theory extended by cognitive and aesthetic needs (Zelenka \& Pásková, 2012); it explains the needs between the relationship of travel intentions and the 
perceived risks. Level 1: Physiological needs: In tourism, physiological needs are connected to gastronomy and accommodation. In the relationship between the intention to travel and the perceived risks; the health safety needs of the supply side are usually concentrated on the current conditions of the traveler amid the COVID-19 pandemic; such as the health status influenced by the COVID-19, loss of a job, travel advisories policies by the government. These can limit the person in performing routine habits and traditions. Level 2: Safety needs: Tourists' safety, calm, and peace are the main requirements of tourists. Calm and peace are prerequisites on physical and mental nursing. The service industry in a tourist destination is based on the provision of a friendly atmosphere, safety, serenity, and peaceful conditions related to the natural and human surroundings. Level 3 and 4: Social needs: These are the needs of esteem connected with self-confidence or esteem from others. In the case of tourism service and hospitality, uniqueness and hosts' courtesy are needed. Another important point is to possess the kindness to treat the personal risks perceived by travelers amid the COVID-19. Level 5 and 6: High category needs: Cognitive and aesthetic such as knowledge and understanding the lifestyle of the tourist destination, heritage, and traditions. The final stage, Level 7: Self-actualization: In tourism, the level of self-realization is dependent on a particular tourist destination locality, structure, and quality of tourism services.

\section{Risk Perception}

In general, Bhasin (2018) defined risk perception as an uncertain, probabilistic potential future outlay. Risk perception can also be explained as the subjective evaluation of the risk of a threatening situation based on its features and severity (Moreira, 2008; Sjöberg et al., 2004). It means that there is a form of ambiguity or uncertainty of the customers when bearing in mind buying a new product or service. The level of the uncertainty of a consumer depends upon the worth value of the relevant product or service. Regardless of whether such perceived risk does exist or not. Perceived risk is only a one-sided concept. It differs from people to people and varies from time to time. Yazid et al. (2018) said that each tourist may perceive different levels of risk associated with the same outcome. Broadly, risk perception is usually used to describe a concept of people's attitude and intuitive judgment towards risk (Cui et al., 2016). Wulandari et al. (2018) added that perception has a greater influence on travel decision-making than reality. To date, even the concept of perceived risk discussed in the literature, scholars have had difficulties in defining it (Boksberger et al., 2007; Cho et al., 2018). In the economic field, the concept of risk was introduced in the 1920s where a decision-making study was under economic and financial areas (Hashim et al., 2018). Bauer (1960) was the first to identify risk perception in the context of consumer behavior within the marketing discipline (Lenggogeni, 2015). Then, the idea of risk has become a standard inventory of consumer behavior literature (Pike \& Ryan, 2004). Consumer behavior research usually defines risk perception in terms of uncertainty and consequences (Campbell \& Goodstein, 2001; Hasan et al., 2017). In the tourism context, perceived risk is often observed to get a better understanding of the complexities of choice and decision-making process by potential tourists on purchasing the tourism products and services. The risk is considered as an essential factor that influences tourist's behavior, as tourism is an intangible service that is exposed to potential risks and threats (Hashim et al., 2018). A single harmful incidence can change the perception of risk associated with a destination and decrease tourist arrivals (Chew \& Jahari, 2014; Carter, 1998; Khan et al., 2019). The tourists might doubt that the product or service cannot meet 
their expectations or that is the collection of factors, which are beyond the control during the consumption process (An \& Fu, 2005; Cui et al., 2016).

Throughout the development of perceived risk study, many experts have formed various methods to describe the factors or the dimensions of perceived risk. Moutinho (1987) proposed four factors that determine the level of perceived risks: past behavior, information, personality and level of risk awareness. He emphasized that risk perception plays a certain role in raising the awareness of tourists on the consequences of loss. Meanwhile, Lenggogeni (2015) classified the dimensions into four different sets: time loss, hazard loss, money loss, and ego loss. Then, another study, Kaplan et al. (1974) proposed five dimensions of risk perception including performance, financial, psychological, physical and social. Um et al. (2006) in Hashim et al. (2018) incorporated slightly different classification such as equipment, finance, physical, psychological, satisfaction, social, and time. Chen \& Zhang (2016); Hasan et al.
(2017) have also made an exceptional criterion for risk perception; e.g., mass communication risk, this category is yet to be found in other classification methods. Hashim et al. (2018) classified the dimensions of risk perception into functional risk and psychological risk only. The dimensions include crime risk, disease risk, natural disasters, unhygienic, transportation, and culture or language barriers (Hasan et al., 2017). However, Lenggogeni (2015) argued that there is no model, which can be extensively used to investigate individuals' perceived travel risks. Finally, Brooker (1984) combined the time loss dimension of Roselius (1971) and all the five dimensions proposed by Kaplan et al. (1974); it includes social risk, financial risk, physical risk, psychological risk, performance risk and time risk (Lenggogeni, 2015). Concerning the validity and reliability of this study, the researchers prefer to use the selection concept of risk perception proposed by Brooker for the analysis.

Social risk is the risk that the selection of service providers will negatively affect the perception of another individual about the

Figure 1.

Research Model

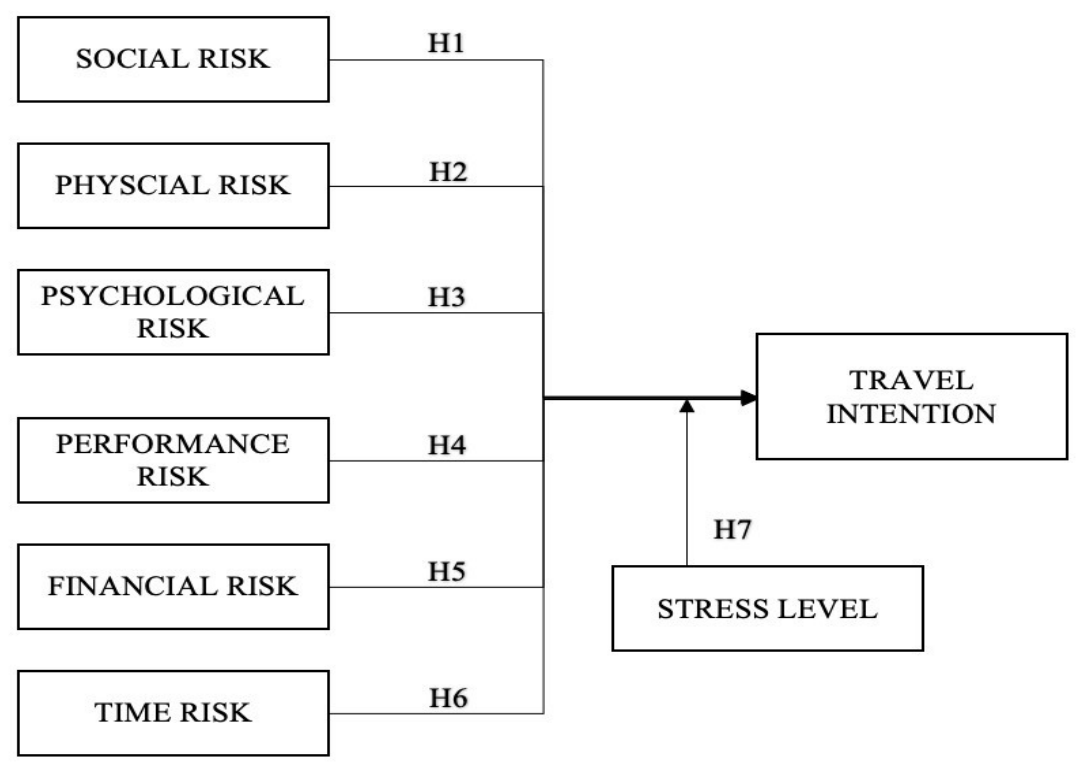

Source: Authors 
purchaser. It refers to the fear associated with the judgment coming from both societies, which are directly and indirectly related to the tourist. Social risk is broadly recognized among many scholars. Hasan et al. (2017) listed the studies where social risk is found to have a notable relationship with decision-making and travel intentions such as Liu \& Gao (2008), Li (2010), Casidy \& Waymer (2016), etc. Hence, the researchers proposed:

H1: There is a significant relationship between social risk and post-pandemic travel intention of international tourists.

Psychological risk is the possibility that selection or performance of the producer will harm the consumer's peace of mind or selfperception (Lenggogeni, 2015). In the tourism field, most studies combined psychological risk and social risk into one category (sociopsychological risk); e.g., Qi et al. (2009). However, many scholars such as $\mathrm{Hu}$ (2011), Liu et al. (2013), and Hasan et al. (2017) have also examined psychological risk separately on the relationship with travel intention. Thus, the authors proposed:

H2: There is a significant relationship between psychological risk and post-pandemic travel intention of international tourists.

Physical risk stands for the possibility that a trip will lead to physical danger or injury (Cho et al., 2018). Artuğer (2015) discussed physical risk in the context of terrorism and natural disaster in travel and tourism, but there are only fewer studies concerning the threat of disease as physical risk to the intention to travel. Since the COVID-19 outbreak was announced as a global pandemic by the world health organization in February 2020, the idea is clear that the potential tourists would fear contracting the disease while traveling internationally. Hence, this was proposed:

H3: There is a significant relationship between physical risk and post-pandemic travel intention of international tourists.
Performance risk is closely related to the satisfaction of the service or product bought. It can be measured in a comprehensive way, such as travel value, environment, landscape, attraction, entertainment, infrastructure, accessibility, and relaxation (Chi \& Qu, 2008; Yu \& Goulden, 2006; Cho et al., 2018). When the pandemic is over, the DMOs might need to readjust the situation and rebuild the destinations. This will affect the quality of the services and products offered to tourists. Therefore, the authors proposed:

H4: There is a significant relationship between performance risk and post-pandemic travel intention of international tourists.

Financial risk is the risk that the service bought will not attain the best possible monetary gain for the consumer. In the travel and tourism context, financial risk involves the fear of losing the money invested in the tourism product or service (Cho et al., 2018). Many scholars have confirmed the impact of financial risks on tourist's behavioral intentions including Artuğer (2015), Wulandari et al. (2018) and Khan et al. (2019). The tourists might not be willing to spend their money on international travel due to the economic uncertainty triggered by the pandemic. Hence, the authors proposed:

H5: There is a significant relationship between financial risk and post-pandemic travel intention of international tourists.

Time risk is described as the possibility that the consumer will waste time, lose convenience, or waste effort in getting a service redone (Lenggogeni, 2015). According to the studies on tourism risk dimensions in recent years, time risk is among seven commonly included dimensions (Hasan et al., 2017). In the context of post-pandemic, the potential tourists might be worried that they will have to stay for a longer time in the destinations due to the sudden closure of a country as it happened 
earlier to many countries during the COVID-19 outbreak. Thousands of tourists were stuck in foreign countries for a couple of weeks or months. Therefore, the authors proposed:

H6: There is a significant relationship between time risk and post-pandemic travel intention of international tourists.

\section{Stress During Quarantine}

Quarantine and isolation are commonly used to help strengthen public health by preventing exposure to people who have or may have a contagious disease. Looking back to the SARS outbreak in 2003 and 2014-2015 Ebola outbreak in West Africa, it demonstrated that infectious disease could be contained if the implementation of the timely measures were taken such as early identification of infected people and contact tracing, also timely quarantine and isolation measures. The previous study showed that quarantining was found to be predictive of a high level of depressive symptoms, even three years after the outbreak. An investigation conducted in Toronto among the general populations put under quarantine in Canada during the SARS outbreak showed that a substantial proportion of quarantined persons are distressed, and the evidence showed the proportion that displays symptoms of posttraumatic symptoms disorders (PTSD) and depression.

Among SARS survivors, a study showed that $10-35 \%$ reported having anxiety, depression or both at one month after discharge. SARS survivors had higher stress levels during the outbreak and persisted one year later. Instead, in the recent COVID-19 outbreak, a study conducted in China found that more than half of the respondents rated the psychological impact of the outbreak as moderate or severe and one third reported moderate-to-severe anxiety (Wang et al., 2020). To the researchers' knowledge, there are no new findings for the association of quarantine and stress levels during COVID-19 so far. Nevertheless, a recent study in South Korea suggested that individuals under quarantine could experience boredom, loneliness and anger during the outbreak of COVID-19 (Park \& Park, 2020). The psychological impact of quarantine can be long-lasting and substantial.

To date, there is no study concerning the influence of stress level on the relationship of risk perception and post-pandemic travel intention specifically. However, many scholars have discussed the general notion on the change of tourist's decision-making due to trauma, anxiety or stress; e.g., Reisinger \& Mavondo (2005) tested the relationships among cultural and psychographic factors, the perception of travel risk and safety, anxiety and intentions to travel and compared the results across Australian and international tourists. Such kinds of literature can be helpful to support a theoretical basis. Hence, the authors propose: H7: The stress level during quarantine amid the COVID-19 outbreak significantly affects the relationship between risk perception and postpandemic travel intention of international tourists.

This study is expected to provide significant and new insights subjected to the relevant fields. There is enough data and information to enable travel agencies to identify the strongest risk factor influencing international travel intention when the pandemic is over. It will help the travel agency firms to have a vision of defining the strategy and plan for rebuilding their business after the pandemic. Then, it gives an overall thought on where the government should invest in. The theory of reasoned action (Ajzen \& Fishbein, 1975; Ajzen \& Fishbein, 1980), whereby "behavioral beliefs are suggested to be the underlying influence on an individual's attitude toward performing the behavior, whereas normative beliefs influence the individual's subjective norm about performing the behavior". Therefore, this study aims to examine the relationship 
between the dimensions of risk perception (i.e., social risk, psychological risk, physical risk, performance risk, financial risk and time risk) and the post-pandemic international travel intention where the stress level of being quarantined due to the COVID-19 outbreak serves as the moderation variable.

\section{Methods}

This research is a quantitative study engaging a purposive sampling method where the researchers collected the data through survey questionnaires, distributed via online and powered by two different digital platforms (Google form \& Wenjuanxing). The questionnaire consists of four comprehensible sections: the first section aims to collect basic demographic information of the samples including gender, age, etc. Besides, some information related to the travel characteristics is also included such as travel preference, favorite destination and so on. The second section is concerning the travel intention where all the items are adapted from Chin et al. (2015) and the third section, is relating to the dimensions of risk perception, and to each category proposed by Brooker (1984) is presented. Lastly, section four is deliberately dedicated to identifying respondents' levels of stress due to the quarantine amid the COVID-19 outbreak using the perceived stress scale (PSS). It is one of the widely used tools used to measure psychological stress. PSS aims to measure the "degree of individuals appraising situations in their lives as stressful" (Cohen et al., 1983). To gather a wider range of samples, the questionnaire was available in five different languages (Chinese, English, French, Indonesian and Italian). Those questionnaires were piloted to 150 (30 for each language version) respondents from China, Nigeria, Cameroon, Indonesia, Côte D'Ivoire, Italy, Ghana, Morocco, Tanzania, and the United States. All versions of the questionnaire were successfully tested reliable (Table 1).
Subsequently, the questionnaires were finally distributed online from 14 April 2020 to 27 April 2020. In a total of 470 respondents (from both online platforms) submitted their responses, but only 409 were able to be analyzed.

Table 1.

Reliability Test Results

\begin{tabular}{cccc}
\hline & \multicolumn{3}{c}{ Cronbach's Alpha } \\
\cline { 2 - 4 } & $\begin{array}{c}\text { Travel } \\
\text { Intention }\end{array}$ & $\begin{array}{c}\text { Risk } \\
\text { Perception }\end{array}$ & $\begin{array}{c}\text { Stress } \\
\text { Level }\end{array}$ \\
\hline Chinese & 0.923 & 0.944 & 0.776 \\
English & 0.821 & 0.875 & 0.885 \\
French & 0.950 & 0.896 & 0.874 \\
Indonesian & 0.925 & 0.935 & 0.835 \\
Italian & 0.772 & 0.877 & 0.75 \\
\hline
\end{tabular}

Source: Data Calculation, 2020

SPSS version 21 was selected as the statistical tool for the data analysis. Firstly, descriptive data analysis was used to obtain comprehension and reference by running a clear cut for the data. The general purpose of descriptive analysis is to summarize, communicate basic patterns, and apply for comprehensible conceptualization as well as generalizing sample findings to the population. Secondly, to test the hypotheses, hierarchical multiple regression (HMR) was used to get the information on how the independent variables simultaneously and partially influence the dependent variable. Besides, the test was also used to find the answer to whether stress level during quarantine amid the COVID-19 outbreak does have a moderate impact on the relationship of perceived risks and travel intention or not.

\section{Results \\ Demographic Information}

The demographic information is essential to attain a deeper understanding of the context of the target study. The respondents from Africa \& Middle East (39.9\%) and Europe (34.8\%) are the two most prominent samples where there are more males $(51.4 \%)$ than females $(48.2 \%)$. 
They are dominated by a group of 18 to 25 years old (46.4\%). Gibson \& Yiannakis (2002); Qi et al. (2009) found that individuals in their 20s are most likely to have the desire for exploration, adventure, and experimentation. Then, the respondents' education backgrounds are relatively high where postgraduate degrees (42.3\%) and undergraduate degree (32.6\%) holders were commonly found. The samples mostly described themselves as a student $(37.4 \%)$ and employees in the private sector $(32 \%)$. Unfortunately, the respondents are predominantly running into the lowest category of income, i.e. below US $\$ 500$ per month (50.6\%) yet the majority of them still happened to travel abroad once a year (54.9\%). Solo traveling $(22.5 \%)$ and traveling with a partner $(22.7 \%)$ are the two most favored methods for international travel by the respondents. Lastly, more than half of the respondents selected destinations with natural attraction for traveling abroad when the pandemic is over (53\%).

\section{Hypotheses Test}

Based on the research objectives, the researchers used the hierarchical multiple regression (HMR) test to examine the influence of risk perception towards international tourists' travel intention with stress level as the moderator. Risk perception items and travel intention were first inserted into Model 1 of the regression analysis. The stress level was also inserted into Model 2.

In Model 1, it reveals that several items of risk perception such as social risk, physical risk, psychological risk and performance risk influence travel intention. The inclusion of stress levels as the moderator variable influences the travel intention as well. Model 1 and 2 had shown an $\mathrm{R}$-value of 0.130 and 0.151 , respectively. It also shows that the stress level influences the travel intention by 0.021 increase in R-Square change. Change in R-Square indicates that among all the variables in Model 1, 13\% can be explained in travel intention. Instead, the stress level in Model
Table 2.

Respondents' Demographic Information

\begin{tabular}{|c|c|c|c|}
\hline Levels & Counts & $\begin{array}{l}\% \text { of } \\
\text { Total }\end{array}$ & $\begin{array}{c}\text { Cumulative } \\
\%\end{array}$ \\
\hline \multicolumn{4}{|l|}{ Area of Origin: } \\
\hline Asia & 118 & $23.9 \%$ & $23.9 \%$ \\
\hline Africa and Middle East & 197 & $39.9 \%$ & $63.8 \%$ \\
\hline Europe & 172 & $34.8 \%$ & $98.6 \%$ \\
\hline North America & 4 & $0.8 \%$ & $99.4 \%$ \\
\hline South America & 3 & $0.6 \%$ & $100.0 \%$ \\
\hline \multicolumn{4}{|l|}{ Age: } \\
\hline 18-25 Years & 229 & $46.4 \%$ & $46.4 \%$ \\
\hline 26-40 Years & 220 & $44.5 \%$ & $90.9 \%$ \\
\hline Above 40 Years & 45 & $9.1 \%$ & $100.0 \%$ \\
\hline \multicolumn{4}{|l|}{ Gender: } \\
\hline Male & 254 & $51.4 \%$ & $51.4 \%$ \\
\hline Female & 239 & $48.4 \%$ & $99.8 \%$ \\
\hline Non-Binary & 1 & $0.2 \%$ & $100.0 \%$ \\
\hline \multicolumn{4}{|l|}{ Occupation: } \\
\hline Student & 185 & $37.4 \%$ & $37.4 \%$ \\
\hline Government Employee & 48 & $9.7 \%$ & $47.2 \%$ \\
\hline Private Sector & 158 & $32.0 \%$ & $79.1 \%$ \\
\hline Self-Employed & 65 & $13.2 \%$ & $92.3 \%$ \\
\hline Others & 38 & $7.7 \%$ & $100.0 \%$ \\
\hline \multicolumn{4}{|l|}{ Education Background: } \\
\hline High School & 82 & $16.6 \%$ & $16.6 \%$ \\
\hline Bachelor's & 179 & $36.2 \%$ & $52.8 \%$ \\
\hline Postgraduate & 209 & $42.3 \%$ & $95.1 \%$ \\
\hline Others & 24 & $4.9 \%$ & $100.0 \%$ \\
\hline \multicolumn{4}{|l|}{ Monthly Income: } \\
\hline Below US\$ 500 & 250 & $50.6 \%$ & $50.6 \%$ \\
\hline US\$ 500-1000 & 103 & $20.9 \%$ & $71.5 \%$ \\
\hline Above US\$ 1000 & 141 & $28.5 \%$ & $100.0 \%$ \\
\hline \multicolumn{4}{|l|}{ Travel Frequency: } \\
\hline Once a Year & 271 & $54.9 \%$ & $54.9 \%$ \\
\hline 2-3 Times A Year & 134 & $27.1 \%$ & $82.0 \%$ \\
\hline > 3 Times A Year & 67 & $13.6 \%$ & $95.5 \%$ \\
\hline None of Above & 22 & $4.5 \%$ & $100.0 \%$ \\
\hline \multicolumn{4}{|l|}{ Travel Duration: } \\
\hline 1-3 days & 89 & $18.0 \%$ & $18.0 \%$ \\
\hline 4-6 days & 219 & $44.3 \%$ & $62.3 \%$ \\
\hline$>7$ days & 171 & $34.6 \%$ & $97.0 \%$ \\
\hline None of Above & 15 & $3.0 \%$ & $100.0 \%$ \\
\hline \multicolumn{4}{|l|}{ Travel Style: } \\
\hline Backpacking & 71 & $14.4 \%$ & $14.4 \%$ \\
\hline Casual & 266 & $53.8 \%$ & $68.2 \%$ \\
\hline Pre-Organized & 97 & $19.6 \%$ & $87.9 \%$ \\
\hline Business & 44 & $8.9 \%$ & $96.8 \%$ \\
\hline Others & 16 & $3.2 \%$ & $100.0 \%$ \\
\hline \multicolumn{4}{|l|}{ Travel Preference: } \\
\hline Solo & 111 & $22.5 \%$ & $22.5 \%$ \\
\hline With Friends & 63 & $12.8 \%$ & $35.2 \%$ \\
\hline With Family & 108 & $21.9 \%$ & $57.1 \%$ \\
\hline With Partner & 112 & $22.7 \%$ & $79.8 \%$ \\
\hline In Group & 87 & $17.6 \%$ & $97.4 \%$ \\
\hline Others & 13 & $2.6 \%$ & $100.0 \%$ \\
\hline \multicolumn{4}{|l|}{ Favorite Destination: } \\
\hline Ecotourism & 28 & $5.7 \%$ & $5.7 \%$ \\
\hline Nature & 257 & $52.0 \%$ & $57.7 \%$ \\
\hline History & 41 & $8.3 \%$ & $66.0 \%$ \\
\hline Culture & 119 & $24.1 \%$ & $90.1 \%$ \\
\hline Amusement Park & 21 & $4.3 \%$ & $94.3 \%$ \\
\hline Others & 28 & $5.7 \%$ & $100.0 \%$ \\
\hline
\end{tabular}

Source: Data Calculation, 2020 
Table 3.

HMR analysis of independent variables and dependent variable

\begin{tabular}{ccccccccc}
\hline \multirow{2}{*}{ Model } & \multirow{2}{*}{$\mathrm{R}$} & R Square & \multirow{2}{*}{$\begin{array}{c}\text { Adjusted } \mathrm{R} \\
\text { Square }\end{array}$} & $\begin{array}{c}\text { Std. Error of } \\
\text { the Estimate }\end{array}$ & $\begin{array}{c}\text { R Square } \\
\text { Change }\end{array}$ & F Change & $\begin{array}{c}\text { Sig. F } \\
\text { Change }\end{array}$ \\
\hline 1 & $.360^{\mathrm{a}}$ & .130 & .117 & 4.651 & .130 & 10.003 & .000 \\
2 & $.389^{\mathrm{b}}$ & .151 & .136 & 4.600 & .021 & 9.957 & .002 \\
\hline
\end{tabular}

a Predictors: social risk, physical risk, psychological risk, performance risk, financial risk, and time risk

b Predictors: social risk, physical risk, psychological risk, performance risk, financial risk, time risk, and stress level

Source: HMR Analysis, 2020

2 explained $2.1 \%$ of travel intention. Furthermore, social risk, physical risk, psychological risk and performance risk in Model 1 and stress level as the moderator in Model 2 has a significant relationship with the travel intention ( $p$-value $<$ $0.05)$. It is observed that a positive association between independent variables (risk perception and stress level as moderator) and travel intention. No association was found between financial risk and time risk with travel intention ( $p$-value $>0.05)$. Social risk and psychological risk show a positive association with travel intention. Among all the independent variables, the stress level has the lowest value that one unit increase in the stress level can only increase 0.112 units in travel intention. The highest value found in social risk where one unit increase in social risk results in a 0.366 increase in travel intention. The other risk perception items such as physical risk, psychological risk, financial risk and time risk have a negative association with travel intention (Table 4).

\section{Discussion}

The HMR test revealed that risk perception simultaneously plays a significant role to determine the intention of potential tourists for international travel. Qi et al. (2009) described the risk as an important factor when considering that international tourism supports this idea. Several studies have also observed the influence of risk perceptions of tourists on their travel intentions (Desivilya et al., 2015; Reisinger \&
Mavondo, 2005; Teitler-Regev et al., 2014; Kim et al., 2019). The relevant studies verified that risk perception is essential to travel decisionmaking. It allows the tourists to postpone their purchasing decisions or completely abandon them (Artuğer, 2015; Wulandari et al., 2018; Kozak et al., 2007; Yazid et al., 2018). Therefore, the significant relationships between perceived risk and intention to travel internationally found in this study are in line with the kinds of literature arguing that the more risk associated with a destination, the less likely an individual will choose to visit (Lee et al., 2012; Sridhar et al., 2016; Yang et al., 2020).

Previous studies had discovered that multiple risk dimensions mainly refer to negative consequences that may occur during travel (Cetinsoz \& Ege, 2013; Cui et al., 2016). Each risk dimension causes an expectation of a probable loss and negatively influences an individual's attitude towards a behavior (Horvat \& Došen, 2013; Hasan et al., 2017). Hence, this study discovered that social risk, physical risk, psychological risk and performance risk, partially demonstrate significant relationships with travel intention. This idea leads to the acceptance of hypotheses one, two, three and four. However, the relationships of the dimensions of risk perception sometimes are inconsistent with the intention to visit a destination such as in Khan et al. (2019). The researchers also found that financial risk and time risk had no significant influence towards 
Table 4.

Coefficient table of independent variables and dependent variable

\begin{tabular}{|c|c|c|c|c|c|c|}
\hline \multirow[t]{2}{*}{ Model } & & \multicolumn{2}{|c|}{ Unstandardized Coefficients } & \multirow{2}{*}{$\begin{array}{c}\text { Standardized } \\
\text { Coefficients } \\
\text { Beta }\end{array}$} & \multirow[t]{2}{*}{$\mathrm{t}$} & \multirow[t]{2}{*}{ Sig. } \\
\hline & & $\mathrm{B}$ & Std. Error & & & \\
\hline \multirow{8}{*}{1} & (Constant) & 18.753 & 1.300 & & 14.431 & .000 \\
\hline & Social Risk & .382 & .099 & .206 & 3.840 & .000 \\
\hline & Physical Risk & -.537 & .119 & -.286 & -4.522 & .000 \\
\hline & Psychological Risk & -.264 & .096 & -.187 & -2.758 & .006 \\
\hline & Performance Risk & .228 & .090 & .149 & 2.535 & .012 \\
\hline & Financial Risk & -.023 & .069 & -.018 & -.336 & .737 \\
\hline & Time Risk & .002 & .102 & .001 & .019 & .985 \\
\hline & (Constant) & 16.696 & 1.441 & & 11.585 & .000 \\
\hline \multirow{7}{*}{2} & Social Risk & .366 & .098 & .197 & 3.715 & .000 \\
\hline & Physical Risk & -.536 & .118 & -.286 & -4.559 & .000 \\
\hline & Psychological Risk & -.262 & .095 & -.186 & -2.777 & .006 \\
\hline & Performance Risk & .241 & .089 & .158 & 2.711 & .007 \\
\hline & Financial Risk & -.023 & .068 & -.018 & -.335 & .738 \\
\hline & Time Risk & -.056 & .102 & -.030 & -.543 & .587 \\
\hline & Stress Level & .112 & .035 & .148 & 3.156 & .002 \\
\hline
\end{tabular}

${ }^{a}$ Dependent Variable: Travel Intention

Source: HMR Analysis, 2020

the respondents' intentions for post-pandemic international travel. The respondents who perceived lower levels on these two dimensions are likely to travel internationally when the pandemic is over. Then, hypotheses five and six are rejected.

The stress level for being quarantined amid the COVID-19 outbreak serves as the mediator variable between the independent variables and the dependent variable. The mediator variable specifies how or why a particular effect or relationship occurs (Yazid et al., 2018). The results of the HMR test showed that there is an association of stress levels between risk perception and post-pandemic international travel intention. Consequently, the researchers accepted hypothesis seven. While stress level significantly influences travel intention, yet the value is extremely low. It is the lowest value in that one unit increase in the stress level can only increase to 0.112 units in travel intention. In Table 2 , it is observed that among all independent variables, social risk has the highest increase in travel intention (0.366). This shows that the association of social risk and stress level is affecting the potential tourists to make the decision for post-pandemic international travel. It means that the fear or anxiety for being judged by their friends and families as well as the local community of visited destinations may hold or even stop them to travel internationally when the pandemic is over.

Following the lead in the literature, the socio-economic status needs of Maslow's need theory (Maslow, 1943), this type of needs are the needs which refer to forming relationships with people to create a sense of social belonging and confirm their ability to develop healthy relationships. At this level, people travel to impress friends, relatives, social groups and other people to gain a higher social status. Nevertheless, a valid correlation between the intention to travel internationally and the high value of social risk perception was found in this study. This paper explains that potential international travelers are mostly concerned about the judgments and fear of stigmatization from their social community when they travel internationally after the pandemic. The resulting repercussions on individual and 
group perceptions, and the effects of these responses on the public collectivity, society and economy, compose a general phenomenon called social representation theory or the social amplification of risk framework. The social amplification of risk can push a traveler, judged by other individuals as an unconscious person, to not undertake a journey due to the difficult circumstances. Social risk perception pertains to not only the self but also the likelihood of close relations of being affected. While such processes can be assumed relevant for all societies, it seems probable that such social risk perceptions are even stronger in the collectivist societies who are most affected by the pandemic than in other individualist cultures who are less affected.

On the contrary, some studies supported the idea that certain dimensions of risk perception including financial and time may have less or even completely no impact on the visit intention of travelers (Qi et al., 2009). This explanation is in line with the findings of this paper whereby the variable of financial risk and time risk statistically show no sign of a relationship with the dependent variable (travel intention) in which moderated by the variable of stress level of being quarantined due to the COVID-19 outbreak. This reflects the idea that despite the economic downfall caused by the pandemic, the respondents may have no burden on spending their money on travel, and the stress during quarantine can be associated with this behavior. Moreover, the possibility that the vacation will take too much time or be a waste of time (Qi et al., 2009) appears as a non-threatening factor as well. The respondents may have undergone difficult times during the quarantine, many of them stayed indoors for at least two to three months due to the growing trend of "stay at home" policies issued by many governments across the world, and not to mention, some countries such as China and Italy where strict lockdown was applied. The pressure resulted from this phenomenon may trigger a higher tendency to spend more time outside their houses to satisfy their travel needs.

The researchers believed that understanding the relationships between the variables of this study would be beneficial for those who have been hit hard by the pandemic including local governments, NGOs and the business operators in the tourism industry in particular. This paper provides the perspective of the future markets in which the marketers can list the tasks to know how the perception of risk is integrally related to travel decisions (Qi et al., 2009). Besides, understanding risk perception is also important, especially in contributing to sustainable growth in the tourism industry since it helps tourist operators to manage the business by considering an unexpected event to minimize risks and thus maximize profit by providing a pleasant environment for tourists (Yazid et al., 2018).

Nevertheless, this study is limited to the perspective of potential tourists for international travel. It is highly suggested that future studies examine the travel intention for domestic travel, which is equally important to the development of the tourism industry postpandemic. Besides, there are several aspects from the results of this study that require further exploration; for example, evaluating the behavior of tourists concerning their willingness to pay (TWP) with a context of postpandemic as this study revealed that financial risk presents no significance on the intention to travel internationally. The researchers also believed that despite risk perception and stress levels, there are other variables that will significantly influence people's intention to travel when the pandemic is over. This could be a substantial topic for future investigations.

\section{Conclusion}

Concisely, the research objective of this research has been achieved. Social risk is found to be the most significant factor in determining the intention for post-pandemic international 
travel where stress level during quarantine is associated as the moderating variable. The destination marketing organizations (DMOs) should, therefore, prioritize its public relations especially with its host communities to educate the public to avoid stigmatization of people coming from a particular part of the world who have been highly affected by the COVID-19 pandemic. Many other strategies could be developed to appeal to social risk perception such as individual traveling, solitary or isolated destinations, traveling in close groups, traveling shorter distances, traveling to destinations with lower border-entry hurdles, promoting shorter stays at familiar and closerto-home destinations.

While several kinds of literature reported that, the tourism industry is sensitive and has heavily been affected by the COVID-19. Previous studies also found that the tourism sector could survive in a bad economic situation. The results of this study have proven that there is hope for the industry. The tourism industry and its supporting industries will revive and amass their economic losses in time because tourists are still willing to spend to travel.

If the tourism industry is going to be prosperous, then tourism researchers must make efforts to increase the industry's understanding of risk perception. This paper also serves as a recommendation for investors, tour operators, governments in designing its tourism products and services in the context of post-pandemic and the risks perceived by the potential tourists, respectively. Without understanding the intervening effects of one factor on another in the travel decision-making and behavior of individuals, general marketing strategies used by the destinations will be less fruitful in attracting potential travelers.

\section{References}

Ahn, T., Ekinci, Y., \& Li, G. (2013). Self-congruence, functional congruence, and destination choice. Journal of Business Research,
66(6), 719-723. https://doi.org/10.1016/j. jbusres.2011.09.009

Ajzen, I., \& Fishbein, M. (1980). Understanding attitudes and predicting social behavior. Englewood Cliffs, NJ: Prentice Hall.

Artuğer, S. (2015). The Effect of Risk Perceptions on Tourists' Revisit Intentions. European Journal of Business and Management, 7(2), 36-43.

Bhasin, H. (2018, July 17). Perceived risk. Retrieved from https://www.marketing91. com/perceived-risk/\#Definition-ofPerceivedRisk

Chen, H.-B., Yeh, S.-S., \& Huan, T.-C. (2014). Nostalgic emotion, experiential value, brand image, and consumption intentions of customers of nostalgicthemed restaurants. Journal of Business Research, 67(3), 354-360. https://doi. org/10.1016/j.jbusres.2013.01.003

Chin, L. C., \& Leng, L. H., Yuan, N. S., \& Xiong P. Y. (2015). Determinants of travel intention among foreign students in Malaysia-perspective from push-pull motivations [Unpublished Bachelor's Thesis]. University of Tunku Abdul Rahman, Malaysia.

Cho, S.-H., Ali, F., \& Manhas, P. S. (2018). Examining the impact of risk perceptions on intentions to travel by air: A comparison of full -service carriers and low-cost carriers. Journal of Air Transport Management, 71, 20-27. https://doi.org/10.1016/j. jairtraman.2018.05.005

Cohen, S., Kamarck T., \& Mermelstein, A. (1983). Global Measure of Perceived Stress. Journal of Health and Social Behavior, 1983, 24(4), 385396. doi: 10.2307/2136404

Cui, F., Liu, Y., Chang, Y., Duan, J., \& Li, J. (2016). An overview of tourism risk perception. Natural Hazards, 82. https://doi.org/10.1007/ s11069-016-2208-1.

Fuchs, G., \& Reichel, A. (2006). Tourist Destination Risk Perception: The Case of Israel. Journal of Hospitality and Leisure Marketing, 14 (2), 8310. https://doi.org/10.1300/J150v14n02_06 
Gössling, S., Scott, D. \& Hall, M. C. (2020). Pandemics, tourism and global change: a rapid assessment of COVID-19. Journal of Sustainable Tourism, 29(1), 1-20. https://doi.org/10.10 80/09669582.2020.1758708

Hasan, M. K., Ismail, A. R., \& Islam, M. F. (2017). Tourist risk perceptions and revisit intention: a critical review of literature. Cogent Business \& Management, 4(1). https:// doi.org/10.1080/23311975.2017.1412874

Hashim, N. A. A. N., Noor, M. A. M., Awang, Z., Aziz, R. C., \& Yusoff, A. M. (2018). The Influence of Tourist Perceived Risk towards Travel Intention: A Conceptual Paper. International Journal of Academic Research in Business and Social Sciences, 8(16), 92-102. https://doi.org/10.6007/IJARBSS/ v8-i16/5120

Jang, S. S., Bai, B., Hu, C., \& Wu, C. M. E. (2009). Affect, travel motivation, and travel intention: A senior market. Journal of Hospitality \& Tourism Research, 33(1), 51-73. https://doi.org/10.1177/1096348008329666

Kaplan, L. B., Szybillo, G. J., \& Jacoby, J. (1974). Components of perceived risk in product purchase: A cross-validation. Journal of Applied Psychology, 59(3), 287291. https://doi.org/10.1037/h0036657

Khan, M. J., Chelliah, S., Haron, M. S., \& Ahmed, S. (2017). Role of Travel Motivations, Perceived Risks, and Travel Constraints on Destination Image and Visit Intention in Medical Tourism: Theoretical model. Sultan Qaboos University medical journal, 17(1), e11-e17. https://doi.org/10.18295/ squmj.2016.17.01.003

Khan, M. J., Chelliah, S., Khan, F., \& Amin, S. (2019). Perceived risks, travel constraints and visit intention of young women travelers: the moderating role of travel motivation. Tourism Review, 74(3), 721-738. https://doi. org/10.1108/tr-08-2018-0116

Kim, M., Choi, K. H., \& Leopkey, B. (2019). The influence of tourist risk perceptions on travel intention to mega sporting event destinations with different levels of risk. Tourism Economics, 135481661987903. https://doi. org/10.1177/1354816619879031

Kozak, M., J. C. Crotts, and R. Law. (2007). The Impact of the Perception of Risk on International Travelers. International Journal of Tourism Research, 9(4), 233-242. https://doi.org/10.1002/jtr.607

Lee, C. K., Song, H. J., Bendle, L. J., Kim, M. J., \& Han, H. (2012). The impact of nonpharmaceutical interventions for 2009 H1N1 influenza on travel intentions: A model of goaldirected behavior. Tourism Management, 33(1), 89-99. https://doi. org/10.1016/j.tourman.2011.02.006

Lenggogeni, S. (2015). Travel risk perceptions, travel intentions, and influencing factors: A natural disaster context [Ph.D. Thesis, UQ Business School, The University of Queensland]. UQ eSpace. https://doi. org/10.14264/uql.2015.233

Maslow, A. H. (1943). A theory of human motivation. Psychological Review, 50(4): 370-96. http://dx.doi.org/10.1037/ h0054346

Mody, M., Day, J., Sydnor, S., Jaffe, W., \& Lehto, X. (2014). The different shades of responsibility: Examining domestic and international travelers' motivations for responsible tourism in India. Tourism Management Perspectives, 12, 113-124. https://doi.org/10.1016/j. tmp.2014.09.008

Mohamed, N., \& Othman, N. (2012). Push and Pull Factor: Determining the Visitors Satisfactions at Urban Recreational Area. Procedia - Social and Behavioral Sciences, 49, 175-182. https://doi.org/10.1016/j. sbspro.2012.07.016

Moreira, P. (2008). Stealth risks and catastrophic risks: On risk perception and crisis recovery strategies. Journal of Travel $\mathcal{E}$ Tourism Marketing, 23 (2-4), 15-27. https:// doi.org/10.1300/J073v23n02_02 
Naidoo, P., Ramseook-Munhurrun, P., Seebaluck, N. V., \& Janvier, S. (2015). Investigating the Motivation of Baby Boomers for Adventure Tourism. Procedia-Social and Behavioral Sciences, 175, 244-251. https://doi. org/10.1016/j.sbspro.2015.01.1197

Park, S. C., \& Park Y. C. (2020). Mental Health Care Measures in Response to the 2019 Novel Coronavirus Outbreak in Korea. Psychiatry Investig, 17(2), 85-86. https://doi. org/10.30773/pi.2020.0058

Pike, S., \& Ryan, C. (2004). Destination Positioning Analysis throughaComparison of Cognitive, Affective, and Conative Perceptions. Journal of Travel Research, 42(4), 333-342. https://doi. org/10.1177/0047287504263029

Qi, C. X., Gibson, H. J., \& Zhang, J. J. (2009). Perceptions of Risk and Travel Intentions: The Case of China and the Beijing Olympic Games. Journal of Sport $\mathcal{E}$ Tourism, 14(1), 43-67. https://doi. org/10.1080/14775080902847439

Reisinger, Y., \& Mavondo, F. (2005). Travel Anxiety and Intentions to Travel Internationally: Implications of TravelRisk Perception. Journal of Travel Research, 43(3), 212-225. https://doi. org/10.1177/0047287504272017

Riley, C. (2020, April 15). 'This is a crisis.' Airlines face $\$ 113$ billion hit from the coronavirus. Retrieved from https:/edition. cnn.com/2020/03/05/business/airlinescoronavirus-iata-travel/index.html

Sancho, E. F., \& Álvarez, R. J. (2010). Tourism Destination Image and Motivations: The Spanish Perspective of Mexico. Journal of Travel \& Tourism Marketing, 27(4), 349-360. https://doi.org/10.1080/10548408.2010.48 1567

S jöberg, L., Mo en, B. E., \& Rundmo, T. (2004). Explaining risk perception. An evaluation of the psychometric paradigm in risk perception research. Rotunde, 84, 1-33.

Sridhar, S., Régner, I., Brouqui, P., \& Gautret, P. (2016). Methodologies for measuring travelers' risk perception of infectious diseases: A systematic review. Travel Medicine and Infectious Disease, 14(4), 360-372. https://doi.org/10. 1016/j.tmaid.2016.05.012 Um, S., Chon, K., \& Ro, Y. (2006). Antecedents of revisit intention. Annals of Tourism Research, 33(4), 1141-1158. https://doi.org/10.1016/j. annals.2006.06.003

Wang, C., Pan, R., Wan, X., Tan, Y., Xu, L., Ho, C.S., \& Ho, R.C. (2020) Immediate Psychological Responses and Associated Factors during the Initial Stage of the 2019 Coronavirus Disease (COVID-19) Epidemic among the General Population in China. International Journal of Environment Research \& Public Health, 17(5). https://doi. org/10.3390/ijerph17051729

$\mathrm{Wu}, \mathrm{C} . \mathrm{W}$. (2015). Foreign tourists' intentions in visiting leisure farms. Journal of Business Research, 68(4), 757-762. https://doi. org/10.1016/j.jbusres.2014.11.024

Wulandari, S., Amani, H., \& Athari, N. (2018). The Determinants of Accident Risk Perception, Travel Motivation, eWOM and Travel Intention on Island Tourism Destination. Atlantis Highlights in Engineering (AHE), 2, 348-352. https://doi.org/10.2991/ icoiese-18.2019.61

Yang, Y.,Zhang, H., \& Chen, X. (2020). Coronavirus pandemic and tourism: Dynamic stochastic general equilibrium modeling of infectious disease outbreak. Annals of Tourism Research, 83(2020), 102913. https://doi.org/10.1016/j. annals. 2020.102913

Yazid, A. S., Yusof, M. Y. M., Rashid, N., Ghazali, P. L., Salleh, F., Mahmod, M. S., \& Mahmood, S. (2018). A Mediating Effect of Risk Perception on Factors Influencing Tourist Intention to Travel: A Conceptual Framework. International Journal of Academic Research in Business and Social Sciences, 8(11), 1246-1255. https://doi.org/10.6007/ IJARBSS/v8-i11/5166

Zelenka, J., \& Pásková, M. (2012). Tourism explanatory dictionary. Praha: Linde. 